\title{
A importância de repensar as práticas de leitura na formação inicial da criança
}

\author{
The Importance of Rethinking Reading Practices in Formation Early Childhood
}

Cláudia da Rosa Salquini†, Marinéa da Silva Figueira Rodrigues **

Como citar esse artigo. Salquini,

CR; Rodrigues, MSF. A importância de repensar as práticas de leitura na formação inicial da criança. Revista Mosaico. 2018 Jul./Dez.; 09 (2): 24-31.

\begin{abstract}
Resumo
O presente estudo é uma revisão da literatura que investigou a importância da leitura na formação inicial da criança e sua relevância para a inserção sociocultural como condição essencial para o pleno exercício da cidadania. Para tanto, realizouse uma pesquisa bibliográfica baseada em renomados autores no assunto. A finalidade foi ressaltar a importância dessa temática como condição essencial para a formação de leitores proficientes. Enfatiza o valor do ato de ler, o incentivo da família e da escola. Portanto, conclui-se que se faz necessário que a família e escola estabeleçam uma parceria, para que juntos alcancem um padrão de excelência nos serviços prestados à criança, obtendo assim sucesso escolar Palavras-Chave: Criança; Escola; Família; Leitor.
\end{abstract}

\begin{abstract}
The present study is a review of the literature that investigated the importance of reading in the initial formation of the child and its relevance to the socio-cultural insertion as an essential condition for the full exercise of citizenship. For this, a bibliographical research based on renowned authors in the subject was carried out. The purpose was to highlight the importance of this subject as an essential condition for the training of proficient readers. Emphasizes the value of reading, the encouragement of family and school. Therefore, it is concluded that it is necessary that the family and school establish a partnership, so that together they reach a standard of excellence in the services provided to the child, thus achieving school success.

Keywords: Child; School; Family; Reader.
\end{abstract}

\section{Introdução}

O nosso país carrega um estigma ao longo de sua história, como sendo um país com pouca vocação para a leitura, a ponto de ser recorrente o fato de que o brasileiro não lê. Lê sim, lê pouco. E, é nesse cenário nada confortável que entra o trabalho da escola e, consequentemente, de seus professores, que por sua vez, tem que ser leitores, para poderem ser responsáveis pela mudança desse quadro.

Refletir sobre o modo como a escola e seus professores têm letrado seus alunos e demonstrar as possibilidades de transformação que um bom trabalho pedagógico pode trazer para o processo de aprender a ler e de continuar a ser leitor, essa é a proposta desse trabalho.

\section{$O$ ato de ler}

Segundo Silva (1995, p. 23), “o cidadão é como uma planta que, desde a forma de semente, precisa ser cuidada para que cresça forte e bonita. Assim é a leitura. Para se fazer leitores é necessário cultivar os atos de ler e entender".

$\mathrm{O}$ ato de ler [...] é um ato de abertura ao pensar e pensarse, longe dos prejuízos e pré-conceitos com que o senso comum ilude a maioria dos alfabetizados, oferecendo leituras já prontas, sem levar em conta o sujeito que as produz e suas circunstâncias (YUNES, 2009, p. 15).

A descoberta das letras foi um marco na evolução do conhecimento, pois através dos documentos escritos, a história ganha legitimidade, servindo de referência para as experiências futuras.

Desde que iniciamos nossa vida nesse mundo, vivemos rodeados de palavras. Nossa sociedade é divulgada através da palavra escrita, onde consequentemente, o acúmulo de material impresso é enorme. Mas foi no século XIX, que o ato de ler tornou-

Afiliação dos autores: † Graduada em Pedagogia pela Universidade de Vassouras, Vassouras/RJ

\$Coordenadora e Docente do Curso de Graduação em Pedagogia da Universidade de Vassouras, Vassouras/RJ

Email para correspondência: marinea.rodrigues@hotmail.com 
se cada vez mais comum entre as pessoas, levando a leitura a tornar-se fundamental na formação do leitor (BARBOSA, 1994).

Segundo Barbosa (1994, p. 116) ler é:

[...] uma atividade extremamente complexa. É uma atividade pessoal e secreta, que só podemos observar em seus aspectos exteriores: um leitor diante de um texto. Podemos também tentar observar o que fazemos quando estamos lendo. Mas essa atenção voltada para nós mesmos enquanto lemos é dificultada porque, para se tornar observável, a leitura deve tornar-se consciente. Então o ato de leitura perde a sua naturalidade. ler é uma atividade ideovisual. Podemos dizer que a leitura depende do que está diante dos nossos olhos. A leitura é uma atividade visual porque para ler é necessário haver um texto diante dos olhos, uma certa claridade e, ás vezes, um par de óculos. Mas, a leitura é mais que um exercício dos globos oculares, pois se apoia, por um lado, no que o leitor recebe através do seu sistema de visão e, por outro, nas informações que o leitor tem disponíveis na sua cabeça, na sua estrutura cognitiva.

Corroborando tais ideias, Silva (2005, p. 41), nos alerta que ler não significa a simples decodificação dos códigos linguísticos, mas [...] "participar mais crítica e ativamente da comunicação humana". O ato de ler é por si uma forma do homem se encontrar com a sua realidade sociocultural, já que o texto apresenta sempre uma intencionalidade, a de quem produziu, e por isso "reflete o humano".

Mediante esse universo literário, cabe à escola se posicionar assumindo maior responsabilidade no trabalho com ênfase na leitura, se comprometendo com a formação de um leitor independente, crítico e reflexivo.

Segundo Freire (2008, p. 11) "a primeira leitura que o ser humano começa a fazer é a leitura de mundo, do seu mundo, entre diversos contextos sociais que se encontra inserido". Corroborando tais ideias, Soares (1998) ressalta que a leitura acompanhada da práxis ajuda na compreensão da informação, facilitando a interpretação e posteriormente a compreensão do texto. Pois, aí que estão as primícias da leitura, onde cada indivíduo tem seu jeito particular de ler o mundo e participar do processo de construção, compartilhando suas experiências, opinando com suas ideias, levantando hipóteses e sugestões de acordo com sua ótica, saindo da posição de leitor passivo e se posicionando como leitor sujeito.

Estudos feitos nos últimos anos, baseados nas pesquisas de Ferreiro e Sinclair (1997) levam-nos a compreender que o comportamento leitor é adquirido nos primeiros anos de vida, bem antes de dirigi-lo para essa aprendizagem. "A criança chega à escola, com uma série de ideias intuitivas do seu universo, construindo a partir da observação direta e de sua própria experiência conceitos de mediação, elaborando conclusões sobre o mundo e a realidade" (FERREIRO, 1997, p. 119), desmitificando, assim, a ideia de que as crianças só aprendem quando são ensinadas.

Com base nessa citação, o saber sobre a língua escrita está aquém do conhecimento das letras, pois se nos limitássemos a ela, não passaria de decodificação de símbolos ou sinais.

Rosenblatt (1988 apud PERÉZ; GARCIA, 2001, p. 49) acrescenta que, sendo a leitura uma ferramenta responsável pela construção de sentidos do homem para com o mundo, ler significa:

[...] interpretar e compreender ativa e criticamente uma
mensagem por meio de um processo dialógico (Ramírez
Garrido,1995) indo de encontro com a experiência, as
ideias prévias e o conhecimento do leitor, bem como com
as informações proporcionadas pelo texto e pelo contexto
em que este processo é realizado. Este confronto atribui ao
leitor um papel ativo no processo de leitura, no qual são
realizadas múltiplas transações entre seus conhecimentos e
as informações oferecidas pelo texto e pelo contexto leitura.

O trabalho com a linguagem constitui um dos eixos básicos na Educação Infantil, dada a sua importância para a formação do sujeito, a interação com as outras pessoas, na orientação das ações das crianças, na construção de muitos conhecimentos e no desenvolvimento do pensamento (BRASIL, 1998).

Teberosky e Colomer (2003) afirmam que a linguagem não funciona de maneira isolada: ela é associativa. Do ponto de vista construtivista devemos considerar que a escrita, a leitura e a linguagem oral não se desenvolvem separadamente, atuando de maneira interdependente desde a mais tenra idade. Também no que diz respeito à alfabetização inicial ela acontece em contextos carregados de significados culturais e sociais determinados. Cabe ao professor ter um conhecimento sólido do quanto os processos cognitivos, sociais, culturais e afetivos de cada leitor são acionados no ato de ler.

Para que haja compreensão no tex to é fundamental a utilização de alguns conhecimentos, como: o conhecimento prévio, o conhecimento estruturado, o estabelecimento de objetivos para a leitura, a materialização linguística, a coesão e a coerência. É através do conhecimento linguístico e textual e do conhecimento de mundo, que o leitor constrói os sentidos no texto.

A leitura é uma atividade complexa, antes de qualquer intenção, o leitor deve ter um motivo para fazê-la. Pode ser feita de várias maneiras, de acordo com aquilo que o leitor procura. Tendo alternância nos significados de leitor para leitor, fruto da individualidade de cada um.

Quando lemos uma história, nos envolvemos de tal maneira, nos apropriando dos acontecimentos. Muitas vezes incorporamos os personagens e viajamos para diversas dimensões fazendo uma retrospectiva no tempo e/ou projetamos o futuro. "[...] Posso não 
ter estado numa tempestade, mas se li uma descrição pormenorizada e senti as mesmas emoções daquele que a viveu e narrou, essa experiência vai se tornar parte do meu repertório de vida" (MARIA, 2002, p. 28-29).

Quanto mais se conhece as convenções do gênero, mas fácil abordar o texto com propriedade. Quais as intenções comunicativas do autor? Qual a finalidade dessa leitura, informar, divertir, apresentar uma argumentação, transmitir ordens, vender uma mercadoria ou o quê? Como enfatiza Kleiman (1997, p. 20) "Quanto mais conhecimento textual o leitor tiver, quanto maior a sua exposição a todo tipo de texto mais fácil será sua compreensão." O leitor não deve apenas interessar-se no que o autor vai transmitir, mas acima de tudo ter seu propósito definido para se fazer a leitura.

Quando se trata de uma informação precisa à atenção do leitor estará voltada exclusivamente para aquele fim, ignorando as desnecessárias para o momento. Quando o intuito é estudar, absorvendo conhecimento através do texto, essa leitura deve ser vagarosa, profunda, destacando as ideias chaves, tirando conclusões e fazendo conexão entre o conhecimento já existente e os novos adquiridos.

Vale ressaltar, que nem todos os alunos iniciam na escola em condições similares, existe diferenças devido à realidade de cada um. A primeira etapa do ensino é conhecer e compensar essas diferenças, aproximandoos do universo leitor através de experiências, indagações, contato com a escrita, suas marcas e regras, proporcionando um ambiente rico em escritas, com diferentes portadores, onde o professor se oferece como escritor/leitor, e os alunos observam uma interação ativa com a linguagem escrita (PÉREZ; GARCÍA, 2001).

\section{As Etapas da Leitura}

Segundo Cabral (1986), na visão psicolinguística o processo de leitura se divide em quatro etapas, a saber:

Decodificação-Éaligação entre oreconhecimento dos símbolos escritos com o significado que ele fornece. Menegassi (1995, p. 87), relata [...] "muitas vezes a decodificação não ultrapassa um nível primário de simples identificação visual, pois se relaciona a uma decodificação fonológica, mas não atinge o nível do significado pretendido".

Segundo Kleiman (1993 apud MENEGASSI; CALCIOLARI, 2002, p. 82):

[...] as práticas de leitura como decodificação não modificam em nada a visão de mundo do leitor, pois se trata apenas de automatismos de identificação e pareamento das palavras do textocomaspalavrasidênticasemumaperguntaoucomentário.

Compreensão - Ocorre quando o leitor capta o sentido do texto lido, tendo conhecimento das ideias chaves, identificando a tipologia usada e compreensão clara do propósito do autor. "Ler é interagir com o texto, considerando-se o papel do leitor, o papel do texto e a interação entre leitor e texto" (LEFFA apud MENEGASSI; CALCIOLARI, 2002, p. 85).

Corroborando tais ideias, Menegassi e Calciolari (2002) complementam que, nesse caso, a compreensão só ocorre se houver afinidade entre o leitor e o texto; se houver uma intenção de ler, a fim de atingir um determinado objetivo.

Interpretação - É a fase onde o leitor mostra se de fato houve compreensão, pois é nesse momento que o leitor tem uma ótica crítica, argumentando, opinando, defendendo enfim, perdendo assim o medo de se expor. Muitas vezes, algumas ideias e acontecimentos não estão explícitos no texto.

$\mathrm{O}$ educador e escritor Rubens Alves nos diz: $\mathrm{Na}$ vida estamos a todo tempo a interpretar [...] E a interpretação, todos nós sabemos, é aquilo que se deve fazer com os textos que se lê. Interpretar é compreender (ALVES, 2004).

Retenção - Nesta fase cabe ao leitor ser capaz de absorver as informações das etapas anteriores e aplicálas. A partir de então, fazer analogias, comparações, reconhecendo o sentido de linguagens figuradas ou subtendidas, aplicando em outros contextos refletindo sobre a importância do que foi lido fazendo um paralelo com sua realidade, e com isso, ter um olhar crítico.

A última etapa no processo de leitura é:

[...] a retenção, que diz respeito ao armazenamento das informações mais importantes na memória de longo prazo. Essa etapa pode concretizar-se em dois níveis: após a compreensão do texto com o armazenamento da sua temática e de seus tópicos principais; ou após a interpretação, em um nível mais elaborado (MENEGASSI, apud MENEGASSI; CALCIOLARI, 2002, p. 83).

Portanto, faz-se necessário, que essas habilidades de leitura não sejam vistas na escola apenas como uma técnica ou receita a ser seguida, mas como aprendizagem, onde o aluno reflita, levante hipóteses e interaja sobre o objeto de conhecimento.

\section{A importância da leitura}

Uma das consequências da Revolução Industrial foi à exigência de escolaridade para todos. Com a Revolução Tecnológica do século $\mathrm{XX}$, houve a necessidade da formação de um novo homem, devido a tanta complexidade, levando esse a ser cada dia mais reflexivo.

Há muito tempo se considera a capacidade de ler essencial à realização pessoal, e hoje em dia é cada vez mais aceita a premissa de que o progresso social e econômico de um país depende muito do acesso que o 
povo tem aos conhecimentos indispensáveis transmitidos pela palavra impressa (BAMBERGER, 2006, p. 7).

Segundo Molina (1992), todo cidadão precisa da leitura, seja no campo profissional, seja no conhecimento da legislação, seja para garantir sua integridade enquanto consumidor, ou para se beneficiar dos recursos que a comunidade the oferece. O cidadão leitor é aquele que está sempre bem informado, buscando seus direitos. Formar um leitor crítico significa formar um cidadão crítico e atuante, assim, a leitura não é apenas necessária para vida em sociedade, mas também para que o indivíduo torne-se parte integrante dela em todos os seus aspectos.

Vivendo em uma sociedade informatizada, onde a economia baseia-se nos setores terciários e quaternários cresce as exigências quanto à formação.

Para Soares (1990), as classes dominantes vêem a leitura como fruição, lazer, ampliação de horizontes, de conhecimentos, de experiências, as classes dominadas vêem pragmaticamente como instrumento necessário à sobrevivência, ao acesso ao mundo do trabalho, à luta contra suas condições de vida.

Mas para que esse homem renasça, é necessário que as escolas tenham infraestrutura e os professores mais apoio no trabalho com ênfase na leitura; ou seja, uma educação de qualidade.

Antes mesmo de se fazer um investimento no processo de aprendizagem da leitura, deve-se empenharse com afinco num trabalho de pós-alfabetização.

$\mathrm{O}$ pesquisador francês Jean Foucambert segundo Barbosa (1994) defende a mudança termológica, propondo o uso da palavra "leiturização" em lugar de alfabetização. Muito mais que a mudança do nome é a mudança do conceito. Deixando o foco de ser o processo de decifração da escrita baseado na correspondência grafo fonêmica, dando ênfase às estratégicas que possibilitem o indivíduo construir sentido e recolher informação a partir do texto escrito.

O trabalho com leitura em sala de aula é apresentado por Solé (1998) em três etapas de atividades com o texto: o antes, o durante e o depois da leitura. Afirma que as estratégias de leitura são as ferramentas necessárias para o desenvolvimento da leitura proficiente. Sua valorização permite compreender e interpretar de forma autônoma os textos lidos e sinalizar para o professor a importância em desenvolver um trabalho efetivo no sentido da formação do leitor independente, crítico e reflexivo.

A maioria das atividades escolares é voltada para avaliar a compreensão da leitura dos alunos, deixando de lado, o ensino de caminhos estratégicos as quais formarão um leitor competente.

Quando ensinadas a ler de forma apropriada, as crianças não encontram tantas dificuldades. Segue algumas estratégias:
Para antes da leitura: antecipação do tema ou ideia principal a partir de elementos paratextuais, como: título, subtítulo, do exame de imagens, de saliências gráficas e outras.

Atividades durante a Leitura: confirmação, retificação das antecipações ou expectativas criadas antes da leitura; localização ou construção do tema ou da ideia principal; anotar as palavras desconhecidas e procurar seus sinônimos consultando um dicionário; formulação de conclusões de sentido do texto que não estão escritos literalmente, baseando-se em outros textos; vivência; cultura; valores; levantamento de hipóteses respeitando a sequência do enredo; reconhecimento de palavras; busca de informações que complementam os sentidos no texto; construção do sentido integral do texto; identificação do propósito do autor; identificação de referência a outros textos; ligação de novas informações ao conhecimento anterior.

Para depois da leitura: construção da síntese semântica do texto, utilização do registro escrito para melhor compreensão; troca de impressões a respeito do texto lido; relação de informações para tirar conclusões; avaliação das informações ou opiniões emitidas no texto e avaliação crítica do texto.

Para formar leitores precisamos nos apaixonar pela leitura. E para que o indivíduo tenha gosto pela mesma é necessário que ela tenha significados para ele, pois quando não há uma afinidade, o resultado final é pouco expressivo.

Barbosa (1994, p. 121) acrescenta que a leitura apresenta muitas faces, já que há algum tempo vivemos uma mudança qualitativa da concepção sobre o ler. "Ler é uma atividade voluntária, inserida num projeto individual e/ou coletivo". Sendo assim, o leitor se defronta com uma diversidade de situações sociais, devendo, portanto estabelecer estratégias adequadas, de acordo com a intenção que tem ao ler. "Ironicamente, a única estratégia ensinada pela escola - a oralização da escrita - revela-se pouco eficaz em todas as situações de leitura do mundo contemporâneo". Para tanto, distinguimos, nas situações de leitura possíveis, seis grandes grupos:

Leitura de Informação - É a situação de comunicação por excelência, tendo por objetivo completar uma lacuna no nosso conhecimento sobre aspectos da vida cotidiana, por exemplo. Refere-se a leitura informativa dos jornais, revistas, instruções diversas, normas, regimentos etc. O leitor toma conhecimento do conteúdo da mensagem, sem se preocupar com o registro duradouro da informação. Geralmente, a leitura é rápida e precisa, sem envolvimento afetivo pessoal.

Leitura de consulta - É utilizada quando necessitamos de uma informação pessoal. Utilizamos, portanto vários materiais: dicionários, anuários, catálogos, enciclopédias, jornais, revistas etc. É um tipo de leitura muito particular, pois toda a atenção perceptiva obedece 
à intenção de localizar a informação visada.

Leitura para a ação - É frequente e mecânica. Leitura rápida, seletiva, de lançar os olhos; orienta ou modifica um comportamento ou ação. Encontramos essa leitura nas placas de sinalização, de orientação, de avisos, de instrução, de cartazes de rua, receitas de bolo etc.

Leitura de reflexão - Leitura mais densa, caracterizada por momentos de pausa para reflexão e apreensão do conteúdo. Oatode ler toma uma forma silenciosa, integral, com retornos constantes às ideias já desenvolvidas. Geralmente esse tipo de leitura é utilizado em teses, ensaios, obras filosóficas, literárias etc.

Leitura de distração - tem por objetivo o relaxamento, a distensão, a evasão, a aventura, o passar do tempo. Esse tipo de leitura coloca em jogo uma disponibilidade afetiva, emocional e encontra certa resistência na tradição escolar, por se tratar de uma leitura sem objetivos culturais ou educacionais explícitos. É a leitura do puro prazer, mas exige do leitor um domínio perfeito do ato de ler.

Leitura da linguagem poética - Nesse tipo de leitura, o leitor além de buscar o conteúdo, visa também se deleitar com a sonoridade das palavras. Pode ser, por exemplo, uma poesia cujo prazer do conteúdo está ligado também ao prazer da forma, à dimensão musical das palavras ou do texto. $\mathrm{O}$ ato de ler toma uma forma mais lenta a fim de tornar exequível seja uma vocalização efetiva seja uma pronúncia interior acentuada

\section{Incentivo dos pais à leitura}

Apesar da escola estar encarregada de desenvolver saberes de leitura a toda a população, a participação da família na construção do leitor é incontestável.

A criança que nasce num ambiente familiar repleto de livros, onde pai e mãe estão sempre lendo, é despertada no hábito de ler. Por isso, a criança deve ser encorajada, incentivada desde cedo a adentrar no mundo da leitura, antes mesmo de aprender a ler. O incentivo da família é primordial para que a criança seja leitora e pode ser manifestado em pequenos atos como: canções de ninar, histórias na hora de dormir, compra de livros, jornais, revistas etc. (NASCIMENTO; BARBOSA, 2006).

Se os pais querem que os seus filhos adquiram hábitos de leitura, também devem fazer dela um hábito: "Os pais que leem, aqueles que já têm eles mesmos o hábito de leitura desenvolvidos, podem ficar tranquilos quanto ao fato de que seus filhos serão bons leitores." (SANDRONE; MACHADO, 1991, p. 11).

Corroborando tais ideias, Souza (2004, p. 38) acrescenta:

Infelizmente, não poucas crianças têm contato com adultos - pais, professores e outros - que recomendam a leitura, falam em livros e autores "clássicos", mas, na verdade, não são leitores nem se interessam pela leitura. Apesar de bem-intencionados, essas pessoas, adeptas da filosofia do "faça o que eu digo, não faça o que eu faço", costumam descrever a literatura de forma bastante idealizada. Lembram-se de comentar, por exemplo, que a leitura, como muitas coisas boas da vida, exige esforço e que o chamado prazer da leitura é a construção que pressupõe treino, capacitação e acumulação. $\mathrm{O}$ contato com adultos pseudoleitores e com idealizações infelizes a respeito da literatura e da leitura, de qualquer forma, tenho certeza, não tem contribuído para a formação de novos leitores.

Desta forma, "os pais que não têm, eles próprios, o hábito de ler deveriam repensar na importância de tentar mudar de comportamento, tanto em benefício dos seus filhos quanto de si mesmos". (SANDRONE; MACHADO, 1991, p. 12). As crianças percebem claramente quando seus pais não possuem hábitos de leitura, principalmente se são cobradas, mas não veem neles esse comportamento.

\section{A influência do comportamento do Educador na formação do Sujeito Leitor}

Em nosso país não há tradição de leitura entre os professores. E ao pensarmos em leitura, não podemos desconsiderar a formação do professor, que é um dos principais agentes de formação de leitores. $\mathrm{O}$ aluno que recebe incentivo em casa, se ao chegar à escola não se deparar com um professor que ame e estimule a leitura, esse aluno pode perder o gosto pela mesma.

Abramovich (2004, p. 61), nos traz uma realidade intrigante, provocando uma séria reflexão individual:

Como falar mais de encantamento da história, das emoções sentidas e vividas pelos personagens, das sofrências e alegrias, dos sufocos e deslumbrâncias, se eu deixei passar batido tudo isso em mim ?? Como fazer a criança ou o jovem lerem se eu leio tão pouco?...

Corroborando tais ideias, Silva (1991) assinala que a leitura tem sido um instrumento esquecido no processo de formação dos professores. Pesquisas relatam justificativas contundentes por parte desse profissional, sendo quase unânimes, onde alegam que: atualmente o professor é marcado pelo desprestígio social da profissão, pelo seu exíguo salário, pelo seu tempo escasso, o que indicadores sinalizam não terem condições para se familiarizarem com a leitura. Chega a ser um paradoxo: “[...] ensinar a ler e a gostar de ler, a formar leitores, quando na verdade esse mediador (professor) não é de fato um bom leitor, não é acostumado com textos variados, não lendo de forma crítica" (FERREIRA; DIAS, 2004, p. 19).

A respeito da responsabilidade da escola e dos professores em relação à leitura, Silva $(2005$, p. 36$)$ indaga: " como (...) incentivar por todos os meios, se os 
próprios meios não são fornecidos às escolas? "(Grifos do autor). A esquiva à leitura, por parte dos alunos, reflete não só algumas das condições materiais, mas especialmente o comportamento do professor na sua prática docente.

Devido às lacunas em sua própria formação escolar o professor utiliza metodologias nas aulas de leitura que não passam de repetição daquilo que ele conheceu como "sala de leitura", banalizando as teorias de leitura e ignorando a intenção de formar leitores críticos e maduros (BETENCOURT, 2000).

Paulo Freire (1998) enfatiza a importância crítica da leitura na alfabetização, cabendo ao professor evidenciar essa importância na formação inicial do leitor; apresentando desafios crescentes a seus alunos, posicionando-os como sujeitos responsáveis pela leitura. Leitura essa, cuja consequência será a produção de sentidos de si mesmo.

Nas séries iniciais, a turma dispõe de somente um professor para todas as disciplinas, tendo esse que se desdobrar para cumprir com o seu currículo. Priorizando ensinar todos esses conteúdos, o professor deixa de fazer o que é de suma importância, incentivar seus alunos a desenvolverem o hábito e o gosto pela leitura. Sendo, mais importante " $[. .$.$] que toda leitura feita na escola é a$ influência do professor sobre os hábitos particulares de leitura" (BAMBERGER, 2006, p. 28).

$\mathrm{O}$ professor não apenas ensina, ele influencia quanto à construção de valores, da identidade e dos hábitos dos indivíduos que educa. A prática docente deve estar orientada para dois tipos de atendimento, no que se refere à formação de leitores: preocupar-se com o aluno e a escolha de textos adequados a sua idade, e as funções da leitura na sua vida escolar e pessoal. Mas também, temos que levar em conta o zelo com o próprio professor. O professor é um profissional inacabado, por esse motivo, aconselham-se aos professores procurarem novos caminhos, novas perspectivas, com a sua formação continuada para a leitura.

Se a formação profissional, em nível de graduação contiver e exigir requisitos específicos no campo da leitura como disciplina, atividades que exijam e multipliquem leituras, teorias atualizadas e adequadas, aplicações justas e criativas, haverá condições do professor resgatar e aperfeiçoar sua história de leitura e qualificar-se para um bom desempenho profissional (COSTA, 2009, p. 36)

Os erros não devem ser perpetuados à nova geração. Qualquer deficiência em seu comportamento leitor alimentará através de um círculo vicioso esse aluno.

\section{Leitura e literatura}

Aliteratura tem o poder de estimular a imaginação, e trazer esclarecimento de muitas perguntas, de achar caminhos através de novas ideias, solucionando questões e aguçando a curiosidade do leitor. Tendo como tarefa civilizar o homem insinuando melhores formas de vida. Ela é um celeiro de cultura. Favorece também o exercício de compreensão, sendo um caminho importante para se chegar a outros textos, pois as crianças com o passar do tempo sentem necessidade de variar os temas de leitura uma vez que, é a forma mais sistematizada de elaboração da fantasia, passando a ter um nível mais elevado de cultura, estimulando a escolha e a crítica de certos textos.

Os contos e as histórias são estratégias para que os alunos conheçam coisas novas; partindo daí a linguagem é construída, sua oralidade é reforçada, surgindo novas ideias, valores e sentimentos.

Seja qual profissional for, se esse não leu um romance, um livro de contos ou de poemas no decorrer de sua vida ele não é completo, sendo deficiente internamente.

Candido (2000. p. 68) acrescenta que:

[...] a literatura é, pois, um sistema vivo de obras, agindo umas sobre as outras e sobre os leitores; e só vive na medida em que estes a vivem, decifrando-a, aceitando-a, deformando-a. A obra não é um produto fixo, unívoco ante qualquer público; nem este é passivo, homogêneo, registrando uniformemente o seu efeito. São dois termos que atuam um sobre o outro, e aos quais se junta o autor, termo inicial desse processo de circulação literária, para configurar a realidade da literatura atuando no tempo. (CANDIDO, 2000, p. 68).

Por isso é de suma importância a literatura nas escolas, onde devemos fazer uma triagem, deixando de lado os materiais que não são coerentes com a realidade de educando e educadores. Limitando-se apenas de leitura oral, reprodução do que foi escrito e fixação de sentidos.

Lobato (1981) nos relata que por meio da literatura fixam-se aspectos da alma de um povo, ou pelo menos instantes da vida desse povo. Segundo esse pensamento é imprescindível que o poder público, além de equipar as bibliotecas com bons materiais à leitura, busque reconhecer o trabalho do docente de modo que esse profissional da educação tenha condições, pelo menos satisfatórias, para ler e se atualizar, efetivando a aprendizagem da leitura como mudança social.

\section{A escola e a formação de leitores letrados}

Assim como acontece com a alfabetização, a escola pode ou não ficar no meio do caminho, o que quer dizer: dar oportunidades para que sua tarefa se cumpra de modo global, transformando então o indivíduo habilitado a leitura em um leitor, ou não, o que pode reverter no seu contrário (ZILBERMAN, 1991, p. 17). 
Portanto um dos primeiros requisitos para que o indivíduo adentre ao mundo letrado, seria proporcionálo circunstâncias que o infiltre nesse meio. E esse é o papel da escola, já que estamos falando nas séries iniciais e leitura, a primeira ideia que temos é a leitura voltada para o letramento, mas também voltamos o nosso olhar para a formação desse leitor enquanto alfabetizado e letrado.

Segundo Costa (2009, p. 23) a atuação da escola na formação de leitores de primeiras letras pode resultar:

[...] acréscimo significativo de valores humanos, sociais, econômicos, científicos, filosóficos, sociológicos, psíquicos, artísticos e tantos outros. A iniciação da criança nas habilidades de leitura abre-lhe portas ao conhecimento. A competência de leitura, adquirida nas trocas que, enquanto leitor, ela realiza, aperfeiçoa-se ao longo da vida e pode mantê-la conectada a toda produção do pensar, agir e criar, realizada pela humanidade e registrada em formato de textos escritos. A força dessa aprendizagem constrói consciência e atitudes eficazes ao longo da vida.

Atualmente, há uma nova definição relativa à formação inicial do leitor que recebe o nome de Letramento, termo que segundo Soares (1999, p. 32), "trata não apenas da aquisição das habilidades de leitura e escrita, mas diz respeito à apropriação da escrita e das práticas sociais a ela relacionadas".

Magda Soares (1998) definiu letramento como:

[...] o resultado da ação de ensinare aprender as práticas sociais de leitura e escrita; o estado ou condição que adquire um grupo socialouumindivíduocomoconsequênciadeter-seapropriado da escrita e de suas práticas sociais (SOARES, 1998, p. 18).

O letramento pode ser definido como o processo de inserção e participação na cultura escrita. Esse processo tem início quando a criança começa a conviver com as diferentes manifestações da escrita na sociedade (placa, rótulos, embalagens comerciais, revistas, jornais etc.) e se prolonga por toda a vida.

Não podemos escolher entre alfabetizar ou letrar, é inconcebível alfabetizar sem letrar. Ao orientar a ação pedagógica para o letramento, não podemos descuidar do trabalho específico com o sistema de escrita. Mesmo valorizando em sala de aula os usos e as funções sociais da língua escrita, não implica deixar de tratar sistematicamente da dimensão especificamente linguística do "código", o qual envolve os aspectos fonéticos, fonológicos, morfológicos e sintáticos. Assim também, ao cuidar da dimensão linguística, visando à alfabetização, não implica excluir da sala de aula o trabalho voltado para o letramento. É equívoco pensar os dois processos como sequenciais, isto é, vindo um depois do outro, como se o letramento fosse uma espécie de preparação para a alfabetização, ou como se a alfabetização fosse condição indispensável para o início do processo de letramento.

Numa sociedade letrada a língua escrita está presente nas atividades cotidianas. Essa mesma sociedade é composta de alfabetizados. Para que a ação pedagógica seja produtiva, devemos contemplar de maneira articulada e simultânea, a alfabetização e o letramento.

Mas para que isso ocorra, há necessidade de mudanças no sistema escolar, pois a prática pedagógica, não vem apenas de melhores teorias, de materiais mais adequados, ou de informações mais acessíveis aos professores. "Melhorar a pedagogia da leitura é, a longo prazo, uma questão política, vinculada a um desejo de mudança" (BARBOSA,1994, p. 142).

Penso que a escola não descobriu, ainda, o potencial mágico da leitura e permanece o ensino de uma leitura instrumental, mecânica, esvaziada de sentido. A escola produz não-leitores, como indaga Kramer (1996), em suas pesquisas? A leitura na escola reduz-se à leitura da escola, organizada pelo registro de notas, provas de livros, fichas, resumos, que ocupam o espaço destinado à fruição da leitura? (RANGEL, 2005,p. 13).

Ao argumentar sobre o papel da escola no incentivo à leitura Zilberman (1991; p.16) afirma que: "a escola tem interpretado esta tarefa de um modo mecânico e estático." Quando utilizamos um texto apenas com a intenção de trabalhar a gramática estamos trabalhando de forma mecânica e estática, não permitindo que o aluno se aproprie do texto, tenha liberdade na leitura e em algumas vezes se aprofunde, e faça suas próprias indagações.

\section{Considerações Finais}

Essa pesquisa vem contribuir para que a Educação repense já nos anos iniciais a formação do leitor. É inconcebível pensar em Educação de qualidade sem que se priorize o estudo da leitura.

Se quisermos que o nosso aluno conquiste independência no ato de ler, precisamos orientar sua leitura na fase inicial para que ele entenda como proceder na tarefa de construção de sentido nos textos que forem surgindo ao longo da caminhada escolar de sua vida.

Ler é muito mais que uma simples decodificação, é muito além da compreensão, é saber ler, entender o que foi lido, interpretar o sentido do que foi lido e criticar essas informações trazendo-as para nosso cotidiano dando nossas opiniões, fazendo paralelos entre o aprendido no processo de leitura e na vida. A chamada leitura de mundo. Sendo assim, concluímos que a leitura é um manancial de pesquisas e não mera decodificação de símbolos gráficos.

A família ocupa também junto à escola papel fundamental na formação do leitor letrado. Segundo pesquisas, a genialidade está disponível a todos os bebês, e a família é responsável pelo aumento dessa inteligência até onde a vontade e habilidade da criança permitir. Do 
mesmo modo é fato que crianças que possuem o hábito de leitura em família apresentam desempenho escolar superior ao daqueles que não lêem com frequência.

Em consequência das lacunas em sua formação, o professor compromete seu ofício em relação à desenvoltura na formação de leitores; motivo esse, que exige maior flexibilidade da escola oportunizando disponibilidade de materiais, ambiente adequado, profissionais capacitados, programas de leitura desenvolvidos dentro e fora da escola, projetos de incentivo à leitura, enfim. $\mathrm{O}$ objetivo maior da escola é que esse aluno desenvolva uma prática de leitura para vida toda.

\section{Referências}

ABRAMOVICH, Fani. Literatura infantil: gostosuras e bobices. São Paulo: Scipione, 2004.

ALVES, Rubens. Interpretar e Compreender. Folha de São Paulo, 2004. Disponível em http//w w w1. folha. uol.com. br/folha/sinapse/ ult1063u814shtml. Acesso em ; 09 junho 2014.

BAMBERGER, Richard. Como incentivar o hábito de leitura. 7 ed. São Paulo: Ática, 2006.

BARBOSA, José Juvêncio. Alfabetização e Leitura. 2. ed. São Paulo: Cortez, 1994.

BETENCOURT, M. F. A. A leitura na vida do professor. Passo Fundo: Universidade de Passo Fundo, 2000

BRASIL. Ministério da Educação e do Desporto. Secretaria de Educação Fundamental. Referencial Curricular Nacional para a Educação Infantil. Brasília: MEC/SEF, 1998.

CABRAL, L. S. Processos psicolingüísticos de leitura e a criança. Letras de Hoje, 1986.

CANDIDO, Antonio. Literatura e Sociedade. 8. Ed. São Paulo: T. A. Queiroz, Publifolha. 2000.

COSTA, Marta Morais da. Literatura, leitura a aprendizagem. 2 ed. Santa Catarina: Editora IESES, 2009.

FERREIRA, S. P. A.; DIAS, M. G. B. B. A leitura, a produção de sentidos e o processo inferencial. Psicologia em Estudo, Maringá v. 9 n. 3, p. 439-448, set./dez. 2004.

FERREIRO, Emilia. Com todas as letras. Porto Alegre: Artes Médicas, 1997

FERREIRO, Emilia. A escrita ... antes das letras in: SINCLAIR, Hermine (Ed.) A produção de notações na criança: linguagem, número ritmos e melodias. São Paulo: Cortez Editora, 1997.

FREIRE, Paulo. Pedagogia da autonomia: saberes necessários à prática educativa. 7. ed. Rio de Janeiro: Paz e Terra, 1998

. A importância do ato de ler: em três artigos que se completam. 49 ed. São Paulo: Cortez, 2008

KLEIMAN, Ângela. Oficina de leitura: teoria e prática. Campinas: Pontes: Unicamp, 1993.

\section{7.}

. Texto e leitor: Aspectos Cognitivos da Leitura. São Paulo: Pontes,

LOBATO, Monteiro. Literatura comentada. São Paulo: Abril Educação, 1981.

MARIA, Luzia de. Leitura e Colheita. Livros, Leitura e Formação de Leitores, Petrópolis, Vozes, 2002.
MENEGASSI, Renilson José. Compreensão e interpretação no processo de leitura: noções básicas ao professor. Maringá: Revista UNIMAR, v.17, n. 1, pp. 1995.

MENEGASSI, Renilson José; CALCIOLARI, Angela Cristina. A leitura no vestibular: a primazia da compreensão legitimada na prova de LínguaPortuguesa. Maringá: UEM - Acta Scientiarum, v. 24, n. 1, 2002.

MOLINA, Olga. Ler para aprender: desenvolvimentos de habilidades de estudo. São Paulo: EPU, 1992

NASCIMENTO, T. A. S.; BARBOSA, M. L. F. A influência da escola e da família no estímulo à leitura na Educação Infantil. In: BORA, R.; BOTLER, A. (Org.).Caderno de Trabalhos de Conclusão do Curso de Pedagogia. Recife: UFPE, 2006. Disponível em: https://https:/www.ufpe.br. Acesso em: 24 jun. 2015

PÉREZ, Francisco Carvajal; GARCÍA, Joaquín Ramos. Ensinar ou aprender a ler e escrever. In PÉREZ, Francisco Carvajal; GARCÍA, Joaquín Ramos(Orgs). Ensinar ou Aprender a Ler e a Escrever? Porto Alegre: Artmed Esditora, 2001

RANGEL, Jurema Nogueira Mendes. Leitura na Escola. Porto Alegre: Editora Mediação, 2005.

SANDRONE, Laurac; MACHADO, Luiz Raul. A criança e o livro: guia prático de estímulo à leitura. 3 ed. Brasília: Ática, 1991.

SILVA, Ezequiel Theodoro. Leitura na escola e na biblioteca. 3. ed. Campinas (SP): Papirus, 1991.

A produção da literatura na escola: Pesquisas x propostas. São Paulo: Ática, 1995.

$\mathrm{O}$ ato de ler: fundamentos psicológicos para uma nova pedagogia da leitura. 10. ed. São Paulo: Cortez, 2005.

SOARES, Magda B. Alfabetização: em busca de um método?. Educação em Revista. Belo Horizonte: Faculdade de Educação da UFMG, n. 12. P. 44-50, dez. 1990. 1998.

Letramento: um tema em três gêneros. Belo Horizonte: Autêntica,

SOARES, M. B. A escolarização da literatura infantil e juvenil. In: EVANGELISTA, A. A.. M. et al. A Escolarização da Leitura Literária: o jogo do livro infantil e juvenil. Belo Horizonte: Autêntica, 1999.

SOLÉ, Isabel. Estratégias de leitura. 6. ed. Porto Alegre: Artes Médicas, 1998.

SOUZA, Renata Junqueira de (Org.). Caminhos para a formação do leitor. 1. ed. São Paulo: DCL, 2004. TEBEROSKY, Ana; COLOMER, Teresa. Aprender a ler e a escrever: uma proposta construtivista. Porto Alegre: Artmed, 2003.

YUNES, Eliana. Tecendo um leitor, uma rede de fios cruzados. Curitiba: Aymará, 2009.

ZILBERMAN, R. A leitura e o ensino de literatura. São Paulo: Contexto. 1991. 